\title{
Work at the surgical center: risks of the pathogenic suffering of the nursing team
}

\author{
Trabalho no centro cirúrgico: riscos de sofrimento patogênico da equipe de enfermagem \\ Trabajo en el centro quirúrgico: riesgos de sufrimientos patogénicos del equipo de enfermería
}

'Universidade Federal do Rio Grande do Sul. Porto Alegre, Rio Grande do Sul, Brazil.

How to cite this article:

Araujo RL, Glanzner CH. Work at the surgical center: risks of the pathogenic suffering of the nursing team.

Rev Bras Enferm. 2021;74(2):e20190803.

https://doi.org/10.1590/0034-7167-2019-0803

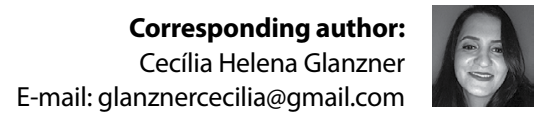

EDITOR IN CHIEF: Dulce Barbosa ASSOCIATE EDITOR: Andrea Bernardes

Submission: 04-13-2020 Approval: 12-21-2020

\begin{abstract}
Objectives: to assess the risks of pathogenic suffering related to the experience of nursing workers in the operating room of a university hospital. Methods: cross-sectional, quantitative study, carried out from 11/2017 to 01/2018 in a university hospital in the South of Brazil. The sample was composed by 159 nursing workers of the units of a surgical center, that answered to the Scale of Evaluation of Pathogenic Suffering at Work. Data was submitted to statistical analysis. Results: the workers present low risk of pathogenic suffering related to the experiences at work, being the results of its factors: Uselessness (1.47 \pm 0.761$)$ - low risk; Indignity $(2.372 \pm 1.035)$ - medium risk; and Disqualification (1.74 \pm 0.903$)$ - low risk. Conclusions: the evaluation of Pathogenic Suffering at Work Scale was positive, predominating low risk for pathogenic suffering of surgical center workers related to professional experiences, because they feel useful, valued and are not indignant about their work, feelings that reflect on the quality of care provided.
\end{abstract}

Descriptors: Work; Surgical Center; Nursing Team; Psychic Suffering; Perioperative Nursing.

\section{RESUMO}

Objetivos: avaliar os riscos de sofrimento patogênico relacionados com a vivência de trabalhadores de enfermagem no centro cirúrgico de um hospital universitário. Métodos: estudo transversal, quantitativo, realizado de 11/2017 a 01/2018 em hospital universitário do Sul do Brasil. A amostra foi formada por 159 trabalhadores de enfermagem das unidades de um centro cirúrgico, que responderam à Escala de Avaliação de Sofrimento Patogênico no Trabalho. Dados foram submetidos à análise estatística. Resultados: os trabalhadores apresentam baixo risco de sofrimento patogênico relacionado com as vivências no trabalho, sendo os resultados dos seus fatores: Inutilidade $(1,47 \pm 0,761)$ - risco baixo; Indignidade $(2,372 \pm 1,035)$ - risco médio; e Desqualificação $(1,74 \pm 0,903)$ - risco baixo. Conclusões: a avaliação da Escala de Sofrimento Patogênico no Trabalho foi positiva, predominando baixo risco para sofrimento patogênico dos trabalhadores de centro cirúrgico relacionado com as vivências profissionais, pois sentem-se úteis, valorizados e não estão indignados com seu trabalho, sentimentos que refletem na qualidade da assistência prestada.

Descritores: Trabalho; Centro Cirúrgico; Equipe de Enfermagem; Sofrimento Psíquico; Enfermagem Perioperatória.

\section{RESUMEN}

Objetivos: evaluar los riesgos de sufrimiento patogénico relacionados a la experiencia de trabajadores de enfermería en centro quirúrgico de un hospital universitario. Métodos: estudio transversal, cuantitativo, realizado de 11/2017 a 01/2018 en hospital universitario del Sur de Brasil. Muestreo formado por 159 trabajadores de enfermería de las unidades de un centro quirúrgico, que respondieron a la Escala de Evaluación de Sufrimiento Patogénico en el Trabajo. Datos sometidos al análisis estadístico. Resultados: trabajadores presentan bajo riesgo de sufrimiento patogénico relacionado a las experiencias en el trabajo, siendo los resultados de sus factores: Inutilidad $(1,47 \pm 0,761)$ - riesgo bajo; Indignidad $(2,372 \pm 1,035)$ - riesgo mediano; y Descalificación $(1,74 \pm 0,903)$ - riesgo bajo. Conclusiones: evaluación de la Escala de Sofriemiento en el Trabajo fue positiva, predominando bajo riesgo para sufrimiento patogénico de los trabajadores del centro quirúrgico relacionado a las experiencias profesionales, pues se sienten útiles, valorizados y no están indignados con su trabajo, sentimientos que reflejan en la calidad de la asistencia prestada.

Descriptores: Trabajo; Centro Quirúrgico; Equipo de Enfermería; Sufrimiento Psíquico; Enfermería Perioperatoria. 


\section{INTRODUCTION}

In the hospital context, the Surgical Center (SC) is considered a complex and restricted area, where elective, where elective surgical procedures are performed, emergency and urgent surgical, aimed at the immediate post-anesthetic and postoperative recovery of patients ${ }^{(1)}$.

The work process in SC aims at the global assistance of patients who undergo anesthetic and surgical procedures. Nursing corresponds to most of the multi-professional team of SC, considering the surgical block, post-anesthesia recovery unit and materials and sterilization center, needing to be trained and qualified to act in different situations that may arise due to the various procedures increasingly complex and technological advances ${ }^{(1)}$.

Thus, the nursing team's performance is relevant important, since it involves from the preparation of materials and necessary equipment - including the specificities of each surgery and patient for the surgical procedure - to ensure individualized assistance, with specific care and, often, high complexity ${ }^{(1)}$, to the performing aseptic techniques, preparation of the operating room where the surgical procedures are performed, surgical instrumentation, related actions to the patient, bureaucratic and management actions of the work teams ${ }^{(2)}$ with the purpose of a curative and individualized care ${ }^{(1)}$, both in the trans-operative and in their anesthetic recovery.

When performing professional activities, the worker experiences satisfaction with his work and sometimes not. Being well in your workplace is a paramount need, because satisfaction is linked to the individual's well-being in all aspects of his/her life, which directly affects the worker's health, quality of life and care provided $^{(3)}$.

In this sense, the working environment can be characterized by experiences that are considered prenunciating of suffering, such as the division of tasks, protocols, routines and rhythms of work. And it is the possibilities of intervention of these experiences that can transform the work activities in satisfactory ${ }^{(4)}$.

Professional satisfaction and lack of recognition are considered important variables associated with interest in work and personal fulfillment of individuals. Although it is possible to prevent or reduce exposure to psychosocial risks, health professionals are often exposed to illness and injury when performing their duties due to inadequate working conditions and biosecurity measures, which can affect the quality of their attention to work ${ }^{(5)}$.

For a favorable working environment, it is necessary to identify the risks of pathogenic suffering experienced at work, in addition to emphasizing flexibility of choices, autonomy of individuals and exchange relationships. These situations allow workers to experience creative suffering and the pleasure of having good experiences at work, managing to adjust reality to their needs. On the other hand, periods of greater repression lead to the use of defenses and pathogenic suffering, because suffering is now avoided and not spoken of.

Pathogenic suffering has worsened, due to the changes in world, which led to the degradation of intersubjective relations and the disarticulation of work collectives, and arises because of the impossibility of adaptation, negotiation and creation in the context of the organization of work, that is, when the margins of freedom in the transformation and desire of subjects, management and improvement of the organization of work have already been used and exhausted. They are signs of individualism and the resulting degradation of cooperation, recognition and conviviality are marks of the worsening of this pathogenic suffering. It occurs when the individual is unable to continue his activities or when he uses resources of denial or emotional euphemism due to the work process and is evidenced by feelings of uselessness, indignation and disqualification related to experiences in the work environment ${ }^{(4)}$.

In the scientific literature, workers' mental health issues have been considered an emerging occupational problem ${ }^{(6)}$; according to the International Labor Organization (ILO), the suffering generated at work is identified as a set of phenomena that presents itself in the body and affects it, putting at risk its health ${ }^{(7)}$. The consequences are underperformance, low self-esteem, high turnover and absenteeism of professionals and violence in the workplace. The unsatisfactory result of the work brings frustration, insecurity, professional devaluation, mental exhaustion, which translates into pathogenic suffering ${ }^{(4)}$.

Nursing is a profession that faces several situations that can generate suffering, mainly among professionals who provide direct assistance to clients in critical situations ${ }^{(8)}$. This also occurs with those who work with patients submitted to surgical procedures, who, besides the support to the other members of the surgical team, need permanent qualification, being their activities linked to the excess of activities, insufficient human resources, lack of equipment or materials necessary to the assistance given to the surgical patient, which over the years leads to physical, emotional and social wear and tear ${ }^{(9)}$.

Faced with the different work situations in a surgical center, existing conflicts, experiences that professionals experience during their work activities and how much this influences the health of workers ${ }^{(9)}$, the potentiality of the Pathogenic Suffering at Work Scale (PSWS) in identifying the risks of pathogenic suffering to which surgical center workers are exposed during the working day is perceived. In face of the complex area that is the SC together with the necessity to understand the illness of the nursing professionals and the deficit of studies about the risks to which the professionals of the area are exposed, the present study is justified. Therefore, based on the mapping of suffering indicators that precede physical and psychosocial damages, the present study aims to collaborate for the formation of new ideas of intervention and/or to adapt the functions of support to the worker's health, for the promotion of occupational health and safety.

From this perspective, the following question arises: Do surgical center workers present a risk of work-related pathogenic suffering? Are feelings of uselessness, indignity and disqualification present in the experience of nursing workers in a surgical center of a university hospital?

\section{OBJECTIVES}

To assess the risks of pathogenic suffering related to the experience of nursing workers in the operating room of a university hospital. 


\section{METHODS}

\section{Ethical aspects}

To ensure the ethical issues involved in conducting this research, the project was sent to/approved by the Research Ethics Committee of the Clinical Hospital of Porto Alegre and the Research Committee of the Nursing School of the Federal University of Rio Grande do Sul (COMPESQ/EE). This study is part of an umbrella project entitled "The Work and Risks of Adoption in Nursing Workers of the Surgical Center of a University Hospital". The study met the national and international guidelines for research involving human beings, Resolution No. 466/12(10).

All participants in the study were invited, and those who agreed to participate signed the Free and Informed Consent Term and answered the instrument individually.

\section{Design, time and location of the study}

This is a cross-sectional study, with a quantitative approach, carried out in the units of the Surgical Center (SC) of a university hospital, located in the capital of the state of Rio Grande do Sul.

The surgical center researched consists of: Outpatient Surgical Center (OSC), Surgical Block Unit (SBU), Post-Anesthetic Recovery Unit (PARU) and Material and Sterilization Center (MSC) ${ }^{(1)}$.

The data collection was carried out from November 2017 to January 2018, through the application of a research instrument by a previously trained team, at which time the participants were invited and informed individually about the objectives of the study.

\section{Population and sample; inclusion and exclusion criteria}

The population of the study was formed by 350 workers of the nursing team of the units of the surgical center of the institution. For the sample, a possible statistical calculation was made to detect a difference in effect size greater or equal to 0.25 , considering a power of $80 \%$ and level of significance of 0.05 . Therefore, it was constituted of 159 nursing workers that were invited in a random way.

It included nurses, technicians and auxiliary nurses who worked in the morning, afternoon, intermediate, night and sixth shift (weekend), of both sexes and with employment relationship with the institution. They were excluded the workers of the units of the surgical center that were distant, in vacations, leave-health or special, that did not accept to participate of the study or presented less than six months of time of service in the current position during the collection of data (it is justified the necessity of at least six months of work in the sector, for the knowledge of the process of work in the area).

\section{Study protocol}

The instrument used was the Pathogenic Suffering at Work Scale, which is composed of 28 items, and comprises three factors: Unnecessity, Indignity and Disqualification in the work environment. The items of each factor were scored using a Likert type scale of 5 points: $1=$ Never, 2 = rarely, $3=$ sometimes, $4=$ frequently, 5 = always. PSWS consists of positive and negative items thus, pathogenic suffering is identified when there are negative experiences and no positive experiences ${ }^{(3)}$. The study protocol also includes questions regarding gender, age, education, marital status, position, type of contract, length of service in the institution, periodic medical examination and time away from work; and questions regarding physical activity, smoking, work shift and sleep were added.

PSWS scores and its factors were dichotomized in three groups: high, moderate and low risk. The higher the average, the lower the feeling of pleasure, being the average above 3.8 a negative evaluation; the average between 2.3 and 3.7, moderate evaluation; and the average 1 to 2.2, evaluation for low risk, considered a positive evaluation ${ }^{(4)}$.

The global score of the scale is obtained through the following criteria: it is considered high when two factors present high risks or one is high and the other medium; the global risk will be medium when the three factors are evaluated as medium risk, two factors are medium and one is low, or when one factor is evaluated as high risk and the other are low; and, finally, the global risk will be considered low when the three factors are so evaluated or two factors are evaluated as low risk and one as medium ${ }^{(4)}$.

The invited participants received the instrument in hand, at which time the objectives were presented and the doubts about the research were clarified. The instrument was collected through an agreement between the parties; thus, it was possible for the worker to respond to PSWS in his/her break or outside his/her work day, in the way he/she felt most comfortable.

\section{Analysis of results and statistics}

The data was organized and double typed in Excel ${ }^{\circ}$ spreadsheet and then analyzed by the Statistic Predictive Analytics Software, version 22.0 for Windows. The descriptive analysis was performed using simple and relative frequencies for categorical variables; and of central tendency (mean or median) and measures of dispersion (standard deviation and quartiles) for continuous ones. In order to evaluate the internal consistency of the scale used, Cronbach's alpha was calculated.

The continuous variables were described by means of mean and standard deviation or median and interquartile range; and the categorical ones, by absolute and relative frequencies. In order to test the normality of the sample, the Kolmogorov-Smirnov test was used; and to compare proportions between groups, the Pearson's chi-square test (polytomic variables), chi-square with Yates's correction (dichotomous variables with an expected frequency higher than 5) or Fisher's exact test (dichotomous variables with a frequency lower than 5 in at least $25 \%$ of the cases). Associations with continuous variables occurred by Pearson's correlation coefficients. Characteristics that had values of $p<0.20$ were included in multiple linear regression analysis (one for each factor) and in the identification of the variables that influenced the scale factors. For this analysis, values of $\mathrm{p}<0.05$ were considered significant ${ }^{(4)}$.

\section{RESULTS}

Most SC workers were female, 131 (81.9\%), with an average age of 46.7 years (SD $=8.9$ ); 94 married $(58.7 \%)$; and most of the workers were nursing technicians, 100 (62.9\%). Among the 
graduates, 35 (21.9\%) had specialization. The average time of service in the institution was 14 years and 11 months $( \pm 10.4)$.

The sector that had the highest participation in the survey was SBU, with 48 (30.2\%) participants, followed by OSC, with 47 (29.6\%); MSC, with 36 (22.6\%); and PARU, with 28 (17.6\%) participants.

Regarding the work shift, 55 (34.3\%), professionals worked at night; 48 (30\%), in the afternoon; 45 (28.3\%), in the morning; and 12 (7.5\%), in the intermediate shift or only on weekends. Regarding health problems, 71 (44.4\%) reported one or two health problems, $148(93.1 \%)$ had periodic institutional medical exams in the last year, and 94 (59.1\%) had no days off work, all in relation to the 12 months prior to the study. Regarding life habits, 93 (58.5\%) reported performing some physical activity, 145 (91.2\%) denied smoking, 108 (67.9\%) reported having a good night's sleep, and 101 (63.1\%) reported sleeping from six to eight hours daily.

The application of PSWS allowed to raise the risks of pathogenic suffering in the work of the nursing team of a surgical center, through the factors Uselessness, Indignity and Disqualification, and their Cronbach's alphas were $0.819,0.847,0.876$, respectively. The general evaluation of the PSWS scale was considered of low global risk since two factors were considered with low risk and one with medium risk.

Table 1 shows the means of the PSWS items, according to their factors, answered by the study participants, considering that the higher the mean, the higher the risk of pathogenic suffering.

The Uselessness Factor was considered low risk (mean $1.49 \pm 0.76)$, evaluated as low risk by 143 (93.5\%) participants, and $10(6.5 \%)$ considered average risk for work-related pathogenic suffering. The highest scores werel feel unmotivated to perform my tasks (1.94 \pm 0.90$)$, and my work is devalued by the organization (1.92 \pm 0.91$)$ - even though the scores are higher, the risk is low. The items my work is meaningless $(1.11 \pm 0.38)$ and my tasks are trivial (1.11 \pm 0.48$)$, with lower averages, are items that offer less risk for pathogenic suffering.

Regarding the second factor of the scale, the Indignity was the only factor considered as the average risk of pathogenic suffering related to the professional experience of workers in the surgical center studied (average $2.372 \pm 1.03$ ), being that 90 (58.1\%) of the participants evaluated this factor as low risk; 62 (40\%) as medium risk; and 3 (1.9\%) participants considered the indignity as high risk for pathogenic suffering at work. The items

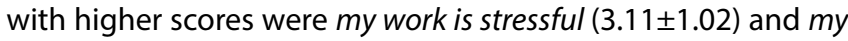
work is tiring (3.08 \pm 1.07$)$, offering medium risk to the workers, and these items presented the highest averages of the scale.

And the lowest scores were I stay in this job for lack of opportunity in the labor market (1.13 \pm 0.48$)$ and my work causes me dissatisfaction (1.42 \pm 0.74 ), offering low risk.

Regarding the Disqualification factor (average 1.74 \pm 0.90 ), the risk was considered low for 126 (80.3\%) participants, 29 (18.5\%) evaluated as medium risk and $2(1.3 \%)$ as high risk. The items with the highest score were I lack the freedom to say what I think about my work (2.27 \pm 1.06$)$ and it is difficult to coexist with my colleagues (1.84 \pm 0.83$)$, and the lowest mean was for the work I do is disqualified by the manager $(1.42 \pm 0.73)$ and my manager treats my work with indifference $(1.50 \pm 0.80)$.

Table 1 - Mean and standard deviation of the items on the Pathogenic Suffering at Work Scale, answered by workers in the surgical center units of a university hospital, Porto Alegre, Rio Grande do Sul, Brazil, 2018 (N=159)

\begin{tabular}{|c|c|c|c|c|}
\hline Factor & Items & Mean & SD & Risk \\
\hline \multicolumn{5}{|c|}{ Uselessness } \\
\hline & My work is devalued by the organization & 1.92 & 0.91 & Low \\
\hline & I feel useless in my work & 1.72 & 1.10 & Low \\
\hline & I consider my tasks insignificant & 1.34 & 0.68 & Low \\
\hline & I feel unproductive in my work & 1.41 & 0.8 & Low \\
\hline & Identification with my tasks is non-existent & 1.45 & 0.8 & Low \\
\hline & I feel unmotivated to perform my tasks & 1.94 & 0.90 & Low \\
\hline & My work is irrelevant for development & 1.35 & 0.81 & Low \\
\hline & My work is meaningless & 1.11 & 0.38 & Low \\
\hline & My tasks are trivial. & 1.18 & 0.48 & Low \\
\hline \multicolumn{5}{|c|}{ Indignity } \\
\hline & My work is tiring & 3.08 & 1.07 & Average \\
\hline & My work is exhausting & 3.11 & 1.02 & Average \\
\hline & My work frustrates me & 1.76 & 0.95 & Low \\
\hline & My work overloads me & 2.89 & 1.00 & Average \\
\hline & My work discourages me & 1.83 & 0.92 & Low \\
\hline & Submitting my work to political decisions is a source of revolt & 2.61 & 1.27 & Average \\
\hline & My work makes me suffer & 1.63 & 0.85 & Low \\
\hline & The submission of my boss to superior orders causes me revolt & 1.89 & 1.01 & Low \\
\hline & I stay in this job for lack of opportunity in the labor market & 1.13 & 0.48 & Low \\
\hline & My work causes me dissatisfaction & 1.42 & 0.74 & Low \\
\hline \multicolumn{5}{|c|}{ Disqualification } \\
\hline & My colleagues devalue my work & 1.79 & 0.91 & Low \\
\hline & I lack the freedom to say what I think about my work & 2.27 & 1.06 & Low \\
\hline & My colleagues are indifferent to me & 1.60 & 0.74 & Low \\
\hline & I am excluded from planning my own tasks & 1.70 & 0.93 & Low \\
\hline & My manager treats my work with indifference & 1.50 & 0.80 & Low \\
\hline & It is difficult to coexist with my colleagues & 1.84 & 0.83 & Low \\
\hline & The work I do is disqualified by the manager & 1.42 & 0.73 & Low \\
\hline & I lack the freedom to dialogue with my leadership & 1.81 & 1.07 & Low \\
\hline & There is mistrust in the relationship between manager and subordinate & 1.79 & 1.05 & Low \\
\hline
\end{tabular}

Note: SD - Standard Deviation. 
Table 2 - Risk of the Uselessness, Indignity and Disqualification Factor in the surgical center units of a university hospital, Porto Alegre, Rio Grande do Sul, Brazil, $2018(\mathrm{~N}=159)$

\begin{tabular}{|c|c|c|c|c|c|c|}
\hline Factor & SBU *\% (n) & OSC $* * \%(n)$ & MSC $* * * \%(n)$ & PARU $* * * \%$ (n) & Total & $p$ \\
\hline Uselessness & & & & & & 0.477 \\
\hline Low risk & $91.5(43)$ & $95.7(44)$ & $96.9(31)$ & $89.3(23)$ & 93.5 (143) & \\
\hline Average risk & $8.5(4)$ & $4.3(2)$ & $3.1(1)$ & $10.7(3)$ & $6.5(10)$ & \\
\hline High risk & 0 & 0 & 0 & 0 & 0 & \\
\hline Indignity & & & & & & 0.397 \\
\hline Low risk & $50(23)$ & $65.2(30)$ & $54.3(19)$ & $64.3(18)$ & $58.1(90)$ & \\
\hline Average risk & $47.8(22)$ & $32.6(15)$ & $42.9(15)$ & $7.1(2)$ & $18.5(29)$ & \\
\hline High risk & $2.2(1)$ & $2.2(1)$ & $2.9(1)$ & 0 & $1.9(3)$ & \\
\hline Disqualification & & & & & & 0.228 \\
\hline Low risk & $75.0(36)$ & $80.0(36)$ & $77.8(28)$ & $92.9(26)$ & $80.3(126)$ & \\
\hline Average risk & $25.0(12)$ & $20.0(9)$ & $16.7(6)$ & $7.1(2)$ & $18.5(29)$ & \\
\hline High risk & 0 & 0 & $5.6(2)$ & 0 & $1.3(2)$ & \\
\hline
\end{tabular}

Note: *Surgical Block Unit; ** Outpatient Surgical Center; *** Materials and Sterilization Center; ${ }^{* * * *}$ Post-Anesthetic Recovery Unit.

After verifying the risk of pathogenic suffering through the results of the PSWS responses, Table 2 presents the analysis of the data according to the factors Uselessness, Indignity and Disqualification, in the different areas studied.

According to Table 2, the PSWS revealed that most of the factors obtained low risk, with this positive result in the sectors evaluated, which represents low risk of work-related pathogenic suffering.

As for the Uselessness factor, 143 (93.5\%) of the participants answered the items of PSWS as low risk, and ten (6.5\%) of these answered the items with values for medium risk, in the different sectors studied.

In the Indignity factor, there were scores for medium and high risk. The medium risk was higher at SBU, with 22 (47.8\%) participants, followed by OSC, with 15 (32.6\%), and MSC, with 15 (42.9\%) participants. The high risk was assessed at SBU by one (2.2\%) participant, followed by OSC, with one (2.2\%), and MSC, with one (2.9\%) participant, which represents a state of alert / limit situation for psychosocial risks at work.

In the Disqualification factor, low risk predominated in 126 $(80.3 \%)$ of the participants in the studied sectors. However, this factor obtained values for average risk in 29 (18.5\%) participants, and the SBU, with the largest number of professionals, totaled 12 (25\%); and, in the high risk, the MSC, with 2 (5.6\%) participants.

In addition to the working context of the different areas, other diverse characteristics may or may not contribute to the emergence of work-related pathogenic suffering.

Comparisons were made regarding multiple linear regression analysis ( $n=142$ ) of the socio-demographic and occupational groups in PSWS, which presented values of $p<0.20$.

In the statistical analysis of the Uselessness Factor, the following were used: age, position/category, number of health problems, last medical exam and work leave. In this analysis, there was no significance between such data. Comparisons of scale factors between categories of socio-demographic and labor variables were also performed, and no statistically significant association between the Uselessness Factor and the other socio-demographic variables was verified.

In the regression analysis for the Indignity factor, the following were used: work shift, age, work time, work leave, being the leave $(p<0.013)$ significant for this factor. In the analysis, it was found that, in relation to the work group, the average comparison between shifts was lower than the other groups $(p=0.041)$, the score was lower in professionals who were working in a period of up to five years ( $p=0.026)$, and the highest score in the scale was in professionals with more than three health problems $(p=0.01)$.

For the Disqualification factor, we used: work shift, number of health problems, time off work, last medical exam, sleeping well - verifying the difference between the groups. It was found that the group that had more than three health problems also had a mean on the scale when compared to the other groups. The same happened with those who were away from work ( $p=$ 0.033), so that this data was not significant for this factor.

\section{DISCUSSION}

In the studied sample, the female sex predominated (81.9\%), that, for tradition and culture, always contributed for this feminization of the health, reinforcing that the nursing is still a predominant feminine profession. However, there is the increasing presence $(18.2 \%)$ of men, reaffirming the emergence of a new trend, that of the masculinization in the category ${ }^{(11)}$.

The average age of nursing workers was 46.7 years $( \pm 8.9)$, age that is within the stage of professional maturation, between 36 and 50 years, being considered stage of the peak of professional recognition; and represents $40 \%$ of nursing professionals in Bra$\mathrm{zil}^{(10)}$. Regarding the length of service in the institution, the sample averaged 14 years and 11 months $( \pm 10.4)$, which highlights the broad experience and professional background of this sample in the same work environment ${ }^{(11)}$.

In view of the results of the PSWS scale, the items of the Uselessness Factor presented low risk, being a positive result for the factor. Despite the low risk, some ten (6.5\%) professionals considered it as medium risk, being 4 (8.5\%) in SBU and 3 (10.7\%) in PARU, a limit situation for psychosocial risks at work, which demands interventions in the short and medium term.

Feelings of uselessness, when performing a work, mean that it has no meaning for the professional or is relevant and meaningful only for the institution ${ }^{(3)}$. Thus, the results reveal that professionals in general feel useful; even though SC is characterized as a dynamic sector, with constant technological advances and with patients at risk of death, professionals feel valued in the performance of their work and in the activities they perform. 
Sometimes the work at the SC can cause dissatisfaction in the workers, due to its organizational characteristics, such as lack of employees, work overload, inappropriate communication, among others. All of this has the possibility of generating pathogenic suffering and causing psychosocial risks in the worker due to stress, anxiety, nervousness and tension ${ }^{(3)}$, reasons that can lead the worker to physical, psychic, emotional suffering and illness.

At SC, the work of nursing is specialized and performed by a team, in which each professional performs a specific task. In these sectors, the dynamics of the care is directed to objective actions, whose intervention, generally, is of technical nature, aiming at the recovery of the patient's health ${ }^{(8)}$, even in the MSC, whose action of the care is indirect.

This dynamic context can sometimes lead the worker to overload, one of the characteristics of the PSWXS Indignity factor. This factor presented average risk for items that questioned whether the work was tiring, exhausting, overloading the professional, and whether the act of submitting the work to political decisions was a source of revolt. This item is related to feelings of injustice, discouragement, dissatisfaction and weariness with the work ${ }^{(4)}$. The SBU, OSC, MSC sectors presented a professional in each sector, with high risk, exposing that they are subject to unpredictability and the constant need for planning and organization of actions, within their work environment. Allied to these conditions are the lack of adequate material and equipment, lack of human resources, the existing conflicts between teams ${ }^{(12)}$, can generate fatigue and overload in professionals. The high and medium risks represent a state of alert for the psychosocial risks at work, being necessary to review attitudes and interventions in the short and long term for pathogenic suffering at work.

There is consensus that work, especially SC, in unfavorable situations causes harm and exposes the worker to occupational diseases, dissatisfaction at work and restrictions on quality of life. The inadequacies of work are related to the processes of illness, with the possibility of temporarily or definitively limiting the worker's life, restricting their social participation and, consequently, their quality of life, and may cause them to withdraw from work ${ }^{(13)}$.

Another feeling that can lead the worker to pathogenic suffering is professional disqualification. Being the last factor of the scale, Disqualification presented low risk in most of its items, which makes this result positive for the work of the professionals in SC, however the average risk was highlighted in 29 participants in the different sectors of the scale application, being that MSC was the only sector in which two workers presented high risk ${ }^{(14)}$.This can represent a state of alert/situation limit being configured as psychosocial risk at work, being likely to generate pathogenic suffering in workers. Measures can be proposed for intervention in the short and long term, favoring the professional to remain healthy. This factor is related to feelings of non-acceptance and/ or admiration for colleagues and managers, lack of freedom to express what the worker thinks and feels in relation to their work ${ }^{(4)}$.

The MSC is an essential unit in the hospital scenario, being responsible for the reception, expurgation, cleaning, decontamination, preparation, sterilization, storage and distribution of the materials used by several sectors in the organizational structure. The work executed in the MSC becomes repetitive and requires attention of those who carry it out; thus, there is difficulty in maintaining, in the sector, stimulated professionals and in synchrony with the tasks to be accomplished ${ }^{(14)}$.

Interpersonal relationships may be affected by poor communication, present in hierarchical management models; work overload and demand for readiness for assignments. These aspects contribute to the possibility of conflicting relations ${ }^{(11)}$. Nursing, inserted in the current capital model, whose focus is based on polyvalence, flexibility, results and the demand for high levels of performance, has a strong tendency not to value the contribution of the worker, impacting his health and often generating suffering ${ }^{(9)}$. And, when this worker is prevented from exercising his or her creative capacity, he or she experiences failure, with possible impairment of his or her health, manifestation of pathologies - psychic and/or somatic - characterizing suffering as pathogenic ${ }^{(15)}$.

This study showed a global result of the scale as low risk of pathogenic suffering; already in another study with health workers in the context of SAMU (Mobile Emergency Care Service), the results of the research indicate that approximately $60 \%$ of the servers have medium risks, and $29 \%$, low risks for pathogenic suffering. In this work context, professionals evaluate that pathogenic suffering refers to emotional exhaustion, expressed by respondents in the submission of work to political decisions, fatigue and wear and tear due to excess overtime and physical effort in care. The researchers conclude that society's recognition of the service provided by SAMU seems to protect them from the pathology of mental exhaustion, the feeling of injustice, discouragement, dissatisfaction and wear and tear with the work ${ }^{(15)}$.

Based on the analyses, we tried to correlate the scale factors and the socio-demographic characteristics. The correlation between the Indignity factor and the distance $(p<0.013)$ was significant for this factor, showing that it is necessary to know the real reasons for the distance and that discussions about the work are fundamental so that feelings of indignation can be reduced and clarified in order to qualify the work. Nursing is in greater number in terms of human resources within hospitals and is one of those responsible for providing direct care to the sick, participating in their rehabilitation ${ }^{(16)}$. In addition, the pace of work, the pressure for results and the deficit in the number of employees for the demands required can damage the physical and psychological integrity of professionals, leading them to leave the job ${ }^{(8)}$.

The team's conviviality in the work environment can become tense, confrontational, and influence the estrangements, but, differently, it also has the possibility of establishing affection and care, where the freedom of expression can contribute to a harmonious conviviality, allowing a cooperative work between the group, which will lead to the team's recognition. When there is recognition of the importance of the mobilization carried out by the workers to perform the task, the work can be pleasant and healthy. However, when the worker's contribution is not recognized, it enters the dimension of pathological suffering and sickness ${ }^{(17)}$.

The study points out that there is a certain lack of knowledge about the relationship of the work process with health and illness issues, which can be justified by unpreparedness or lack of information about occupational risks, to which workers are 
susceptible - for example, work at night, which can generate physiological changes ${ }^{(18)}$. Another example is the work overload of nursing workers, which becomes a barrier in decision making that impacts the institution. This is because, due to the lack of time in the daily practice of the nursing staff, the direct assistance to the patient ends up having priority over the initiatives and projects of organizational change ${ }^{(19)}$, negatively impacting the worker's health condition and further favoring the increase in demands and work overload; consequently, the quality of life related to work is affected ${ }^{(18)}$.

One of the items that generates discomfort in workers is performance evaluations. The performance of professionals is evaluated in the assistance provided, an item that can generate injustices and disappointment. The individualized evaluation contributes to the competition among the workers, to the point of ending up damaging the activities, because if the evaluation is not as good as that of the colleagues, the worker thinks that he/she can lose his bonuses - vetoing desires of transference or advance to which he/she would be entitled - and/or be fired ${ }^{(20)}$.

The lack of recognition goes through quality in work; it is a central concept for the resignification of suffering, enabling the transformation of the organization of work, which can be translated by the experience of injustice, indignation and devaluation for the non-recognition of work done. However, for there to be recognition, it is necessary for the worker to make public the activity he is carrying out, which implies risk, because by showing what one is doing, one also reveals what one is not doing, generating suffering ${ }^{(21)}$. Pleasure experiences are related to the meaning that the individual attributes to his work, to the conditions provided by the organization and to the freedom of use of operational strategies by the worker ${ }^{(3)}$.

\section{Study limitations}

As it is a quantitative instrument, the need for a greater deepening and understanding of the risks of pathogenic suffering through interviews or intervention with smaller groups of surgical center workers is a limitation of this study.

Given the context of the area studied, its constant technological advances and exposure of professionals to psychosocial risks, further studies are suggested that combine innovations in the area with the health of the worker, for comparison and/or confrontation between the findings.

\section{Contributions to the Area}

The results of the study contribute to clinical practice, since they allowed a diagnosis/mapping of pathogenic suffering in nursing workers of the units of the surgical center of a university hospital, an indicator that allows the implementation of interventions and work planning that aim at the qualification of the activities in accordance with the worker's health and with the work context of the different areas.

In this sense, it is important to emphasize the need for expanding research that addresses the psychosocial risks of workers in critical health areas, and it is important to emphasize that pathogenic suffering is one of the main causes of physical and psychosocial damage, and it is essential to carry out interventions prior to workers' health complications. And, also, because it is a university hospital, the study contributes to teaching, counting on the participation of academics in the stages of research and in strategies for improvement as a field of professional training.

\section{CONCLUSIONS}

The results of the study indicate that the nursing workers of the studied surgical center present low risk for pathogenic suffering related to professional experience. These results are positive, considering that the work context of restricted area, dynamic activities, complexity of care, need for constant training, specific and technological knowledge for care of several surgical specialties can offer psychosocial risks related to work.

The workers feel pleasure in carrying out their work, identifying personally and socially with their occupation. In addition, the results show that people who have left work during the year have feelings contrary to those who were not absent or were not happy with the activities they carried out in their daily lives.

After evaluating the scale of pathogenic suffering, it was possible to conclude that the workers consider their work exhausting, tiring, but significant and productive. They feel useful in carrying out their tasks, performing them with dedication and improving the quality of the assistance provided.

\section{REFERENCES}

1. Associação Brasileira de Enfermeiros de Centro Cirúrgico (SOBECC). Práticas Recomendadas SOBECC: Centro de Materiais e Esterilização, Centro Cirúrgico e Recuperação Pós-Anestésica. 7. ed. São Paulo: Manole, 2017. 345 p.

2. Trajano MFC, Gontijo DT, Silva MW, Aquino JM, Monteiro EMLM. Interpersonal relationships in the surgical unit from the perspective of nursing workers: an exploratory study. O Braz J Nurs. 2017;16(1):159-69. https://doi.org/10.17665/1676-4285.20175530

3. Tostes MFP, Silva AQ, Garçon TL, Maran E, Teston EF. Duality between fulfilment and suffering in the work of the nursing staff in operating rooms. Rev SOBECC. 2017;22(1):3-9. https://doi.org/10.5327/Z1414-4425201700010002

4. Facas EP, Mendes AM. Estrutura fatorial do protocolo de avaliação dos riscos psicossociais no trabalho: núcleo trabalho, psicanálise e crítica social [Internet]. 2018 [cited 2019 Mar 06]. Available from: http://nucleotrabalho.com.br/wp-content/uploads/2018/12/1-2013_EmilioPeresFacas.pdf

5. Cadenas NVM. Factores de riesgo laboral en el profesional de salud de Centro Quirúrgico Hospital I Octavio Mongrut Muñoz [Thesis]. Universidad Nacional Mayor de San Marcos). 2015[cited 2019 Mar 15]. Available from: http://repositorioslatinoamericanos.uchile.cl/ handle/2250/173351 
6. Cremades Puerto J, Maciá Soler L, López Montesinos MJ, Pedraz Marcos A, González Chorda VM. A new contribution to the classification of stressors affecting nursing professionals. Rev Latino-Am Enfermagem. 2017;25:e2895. http://dx.doi.org/10.1590/1518-8345.1240.2895

7. Alves Leite TS. (). Occupational stress in nurses employed in emergency and emergency: an integrating review. Rev Human Inov [Internet]. 2018[cited 2019 Nov 1];5(11);268-76. Available: https://revista.unitins.br/index.php/humanidadeseinovacao/article/view/919

8. Ueno LGS, Bobroff MCC, Martins JT, Machado RCBR, Linares PG, Gaspar SDG. Occupational stress: stressors referred by the nursing team. Rev Enferm UFPE. 2017;11(4):1632-8. https://doi.org/10.5205/reuol.9763-85423-1-SM.1104201710

9. Jacques JPB, Ribeiro RP, Martins JT, Rizzi DS, Schmidt, D. R. C. Stress Generators for employees of surgical nursing center. Semina: Ciênc Biol Saúde. 2015;36(Supl-1):25-32. https://doi.org/10.5433/1679-0367.2015v36n1Suplp25

10. Conselho Nacional de Saúde. Resolução no 466/12 [Internet]. 2012[cited 2017 Oct 31] Available from: http://bvsms.saude.gov.br/bvs/ saudelegis/cns/2013/res0466_12_12_2012.html

11. Machado MH, Aguiar Filho W, Lacerda WF, Oliveira E, Lemos W, Wermelinger M, et al. Características gerais da enfermagem: o perfil sócio demográfico. Enferm Foco. 2016;7(ESP):9-14. https://doi.org/10.21675/2357-707X.2016.v7.nESP.686

12. Silva MJM, Nogueira LS, Fontes FLL, Santos ARF, Corado JR, Lacerda ARA, et al. Management activities performed by the nurse in the surgic center: obstacles faced by the professional in the sector. EJCH [Internet]. 2019 [cited 01 Oct 2019];(17):e652. Available from: https:// acervomais.com.br/index.php/saude/article/view/652

13. Dutra FCMS, Costa LC, Sampaio RF. The influence of medical work leaves in the perception of health and quality of life of adult individuals. Fisioter Pesqui [Internet]. 2016 [cited 2019 Jul 03];23(1):98-104. https://doi.org/10.1590/1809-2950/14900923012016

14. Costa CCP, Souza NVDO, Silva PAS, Oliveira EB, Vieira MLC. Working at central supply and sterilization: health implications for nursing workers. Rev Enferm UERJ. 2015;23(4):533-9. https://doi.org/10.12957/reuerj.2015.15934

15. Araujo LKR, Oliveira SS. Mapeamento dos Riscos Psicossociais no SAMU/DF. Psicol Ciênc Prof. 2019;39:e184126. https://doi. org/10.1590/1982-3703003184126

16. Rodrigues LF, Araújo JS. Absenteeism among health workers: an essay the light of occupational medicine. Rev Ciênc Estud Acad Med [Internet]. 2016[cited 29 May 19];1(05):10-21. Available from: https://periodicos.unemat.br/index.php/revistamedicina/article/view/1130

17. Pacheco TP, Silva RMPD. Psychosocial risk for public university workers in Brazil's northern region. Rev Psicol Organ Trab. 2018;18(1):335-44. https://doi.org/10.17652/rpot/2018.1.13388

18. Azevedo BDS, Nery AA, Cardoso JP. Occupational stress and dissatisfaction with quality of work life in nursing. Texto Contexto Enferm. 2017;26(1):e3940015. https://doi.org/10.1590/0104-07072017003940015

19. Van Bogaert $P$, Peremans $L$, Wit $M$, Franck E, Timmermans $O$, Havens DS. Nurse managers' perceptions and experiences regarding staff nurse empowerment: a qualitative study. Frontiers Psychol. 2015;6:1585. https://doi.org/10.3389/fpsyg.2015.01585

20. Duarte A, Dejours C. Le harcèlement au travail et ses conséquences psychopathologiques: une clinique qui se transforme. L'Évolut Psychiatr. 2019;84(I-2):337-45. https://doi.org/10.1016/j.evopsy.2018.12.002

21. Prestes FC, Beck CLC, Magnago TSBS, Silva RM. Pleasure-suffering indicators of nursing work in a hemodialysis nursing service. Rev EsC Enferm USP. 2015;49(3):465-72. https://doi.org/10.1590/S0080-623420150000300015 